\title{
The Acorn Adjustments of Australian Temperatures are in the Wrong Direction
}

\author{
A. Parker ${ }^{1^{*}}$ \\ ${ }^{1}$ School of Engineering and Physical Science, James Cook University, Townsville 4811 QLD,
} Australia.

Author's contribution All work, thoughts, interpretations are done by the author.

Article Information

DOI: $10.9734 / \mathrm{PSIJ} / 2015 / 17270$

Editor(s):

(1) Mohd Rafatullah, Division of Environmental Technology, School of Industrial Technology, Universiti Sains Malaysia, Malaysia.

(2) Abbas Mohammed, Blekinge Institute of Technology, Sweden. Reviewers:

(1) Anonymous, India

(2) R. K. Aggarwal, Department of Environmental Science, Dr Y. S. Parmar University of Horticulture and Forestry, Nauni,

Solan, India

(3) Anonymous, Thailand.

Complete Peer review History: http://www.sciencedomain.org/review-history.php?iid=1001\&id=33\&aid=8854

\section{Short Communication}

Received 6 ${ }^{\text {th }}$ March 2015

Accepted 27 ${ }^{\text {th }}$ March 2015

Published $16^{\text {th }}$ April 2015

\section{ABSTRACT}

We previously discussed as the warming of Australia evidenced by the Australian Climate Observations Reference Network (ACORN) data set is artificially created by the arbitrary correction of the truly measured temperatures making cooler the temperatures of the past [1-4]. Gillham [5] has freshly brought to the attention of the scientific community two old data sets that further support our claim, proving once more how the ACORN corrections are wrongly set up to magnify the warming trend where actually they should rather cancel the urban heat island effect reducing the trend.

Keywords: Measured temperatures; corrected temperatures; ethics in science; scientific debate.

\section{INTRODUCTION}

A proper assessment of warming trends since the end of the 1800 s/beginning of the 1900 s should follow the application of a consistent and stable procedure to a reliable data set cleared of biases as Urban Heat Island (UHI) formation and updated only for the collection of novel results.

*Corresponding author: Email: albertparker@y7mail.com, albert.parker@jcu.edu.au; 
Conversely, the effects of global warming are evaluated by the Australian Bureau of Meteorology (BOM) with a continuously evolving procedure based on a constantly evolving data set, where arbitrary changes of the temperatures collected in the past is the norm rather than the exception. This practice of arbitrarily cooling down the past to magnify the warming has been the subject of our past works [1-4].

In [1] we analysed the temperature records for the Northern Territory of Australia to show that both Alice Spring and Darwin had no warming since the end of the 1800s, and much smaller warmings since 1910, than the adjusted trend proposed by the BOM for the purpose of assessing the effects of global warming.

The work [1] was the subject of a comment by BOM that was not processed following the usual peer review practice, as reported in [2]. The author of an original paper is usually informed of a submitted comment. This author is also customarily asked to submit a reply. Both the comment and the reply then normally undergo the peer review to get published together. In this case, the comment was published first, and then the right of reply was waived to the authors' group by asking a BOM relative to review the reply. The reply was obviously rejected there but published elsewhere inclusive of the imperfect peer review details [2].

In [3] we analysed the temperature records for the state of Victoria, Australia to show that apart from the Urban Heat Island formation about the Melbourne thermometer, there was not too much of warming also in regional Victoria, with temperatures similarly flat since the end of the 1800s and warming much less since 1910 than the adjusted trend proposed by the BOM for the purpose of assessing the effects of global warming.

In [4] we finally proved by comparing the BOM raw and adjusted data that the most part of the warming for Australia is the result of the arbitrary correction of the temperature collected in the past that are cooled down for no plausible reason.

We show here as the recently defined Bureau of Meteorology (BOM) Australian Climate Observations Reference Network - Surface Air Temperature (ACORN-SAT) data set introduces an arbitrary cooling of the temperatures of the past vs. the measured trends as they are described in the contemporary Bureau of Meteorology Climate Data Online (CDO) data set and in historical compilations as the Council for Scientific and Industrial Research (CSIR) Meteorological Data for Certain Australian Localities of 1933 and the Commonwealth of Australia Official Year Book of the Commonwealth of Australia of 1953.

\section{AUSTRALIA HAS NOT WARMED SIGNIFICANTLY OVER THE LAST CENTURY}

Adjustments that cool historic temperatures have almost doubled Australia's rate of warming that is otherwise mostly the artificial warming due to the establishment of urban heat island (UHI) about the thermometer locations. Two additional data sets have been recently brought to the attention of the scientific community by Gillham [5] to support the claim that the Australian global warming is man-made but only through corrections by the local Bureau of Meteorology (BOM).

In 1933, Australian researchers published a document collating all the monthly average temperatures at 226 stations from 1855 to 1931 [6]. In 1953, Australian researchers also published an Official Year Book of Australia which included the mean temperature readings at 44 locations from 1911 to 1940 [7]. Gillham [5] analyzed these two historic datasets $[6,7]$, and compared with the BOM Climate Data Online (CDO) data set which has the recent temperatures at these old stations [8], and the best quality ACORN dataset [9] that is the basis for the assessment of the effects of climate change in Australia. The findings of Gillham are once more that the warming of Australia is manmade but only through corrections to the actual measurements for the past performed for no technical reason.

Gillham's analysis of the 1953 Official Year Book of Australia with mean temperature readings from 1911 to 1940 at 44 locations shows that the historic records had warmer average temperatures before they were adjusted and placed into the ACORN dataset. In the 44 stations listed in the Year Book from 1911-1940, the maxima at the same sites is now about $0.5^{\circ} \mathrm{C}$ warmer while the minima are about the same. The ACORN adjustments therefore cool historic averages by around $0.4^{\circ} \mathrm{C}$, which is about one half of the claimed Australian warming trend of $0.9^{\circ} \mathrm{C}$. 
Gillham then analysed the 1933 CSIR data base of 226 stations from 1855 to 1931 . Much of the oldest data in the 1800s was recorded on screens, sheds and shades until the Stevenson screens were introduced across Australia over the 20 year period but two thirds of the temperatures were recorded on Stevenson screens, and are therefore fully reliable. The average is about $0.5^{\circ} \mathrm{C}$ less than what it is now from 2000 to 2014, further confirming a warming rate of about $0.5^{\circ} \mathrm{C}$ over a century.

As the sites from 1911-1940 were all recorded with modern Stevenson Screen equipment. Therefore, there should be no reason to correct these data. The data recorded before the Stevenson Screen equipment was introduced are certainly less reliable, but their correction downward is not legitimate.

More than the Stevenson Screen issue affecting only a minor portion of the measured temperatures that should be considered without any correction to derive a warming trend, it is eventually the establishment of the Urban Heat Island (UHI) that should be accounted for.

As the villages grown to modern cities around the measuring sites, energy storage and energy release have certainly biased upwards the temperature readings. While in some places the UHI effect could have been warming the thermometers also in the first half of the last century, in others the establishment of a $\mathrm{UHI}$ is certainly responsible of a significant warming in the second half of the last century.

The actual "global warming" over a century that is about $0.5^{\circ} \mathrm{C}$ without wrong opposite corrections, would have been very likely a "global cooling" once the UHI effect could have been accounted for.

If Australian thermometers are recording $0.5^{\circ} \mathrm{C}$ higher than they were a century ago, the older stations would need an upward correction rather than a downward correction to compensate for the UHI effect, or the recent temperatures should be adjusted down. This is exactly the opposite of what is done by the BOM that has cooled down the temperatures of the past to produce the artificial warming trend of the ACORN data set [9].

Many other old works, as for example the paper published in 1910 by Hunt [10] discussing the Climate of the Yass-Canberra District, further support the claim the actual warming is actually minimal. Hunt shows temperatures at 10 locations were on average $0.1^{\circ} \mathrm{C}$ warmer in all years before 1909 than in 2004-2013. Hunt also presented the data prior of 1909 with summer and winter mean temperatures at 6 northern Australia locations which average $0.2^{\circ} \mathrm{C}$ warmer than those locations in 2004-2013.

Even though some Australian climate scientists have claimed a likely temperature rise of $4 \mathrm{C}$ by 2100 , this assertion is not supported by any measurement [11].

The contemporary CDO and ACORN BOM data sets propose different results for the same locations. Fig. 1 presents the corrections of the CDO data set [8] introduced in the ACORN data set [9] to permit (according to BOM) an accurate estimations of the Australian temperatures in the in the case of Alice Spring at the centre of the Australian desert.

While the CDO data of other stations are omitted, in the case of Alice Spring the actually measured data are corrected in the direction of magnifying a warming trend.

The CDO data are close to what has been actually measured by thermometers. UHI effects are certainly biasing upwards the trend, that is $+0.0042^{\circ} \mathrm{C} /$ year for the minimum and $+0.0003^{\circ} \mathrm{C} /$ year for the maximum temperatures. The largest warming of the minimum temperature is usually a sign of UHI.

The ACORN data set cut out the pre-1910 data, and shift down the measured temperatures of even more than $1^{\circ} \mathrm{C}$ in the first half of the past century to artificially produce a warming trend of $+0.0136^{\circ} \mathrm{C} /$ year for the minimum and $+0.0180^{\circ} \mathrm{C} /$ year for the maximum temperatures.

The "homogenization" in the ACORN data set provides consistency with the computation of climate models, but certainly not with something actually measured by thermometers.

As shown by [5], the 1874-1931 CSIR [6] and the 1911-1940 Year Book [6] averages temperatures are 28.8 and $28.3^{\circ} \mathrm{C}$ the maximum, and 13 and $12.9^{\circ} \mathrm{C}$ the minimum. According to the CDO data set [7], the average temperatures over the period $1878-1931$ and $1911-1940$ are 29.0 and $28.3^{\circ} \mathrm{C}$ the maximum, and 13.0 and $12.9^{\circ} \mathrm{C}$ the minimum. In the ACORN data set [8], the average temperatures over the period 1911-1940 are $27.8^{\circ} \mathrm{C}$ the maximum, and $12.3^{\circ} \mathrm{C}$ the minimum. This translate in a generalised cooling of the past temperatures of 0.5 the maximum and $0.6^{\circ} \mathrm{C}$ the minimum temperatures respectively. 
Alice Spring is only one of the many stations arbitrarily corrected (or omitted) in the ACORN data set that is now the subject of a parliamentary investigation [1-5]. The Alice Spring temperature record is quite relevant, as this datum is spread out on a very large area with sizeable impact on the warming of Australia as well as the rest of the world.
The global temperature data bases, like the GISS, NOAA and UK Met Office, similarly to the ACORN data base for the specific of Australia, are the result of a continuous "adjustment" of the computational procedure with redefinition of the past records rather than the simple update of the temperature records in the supporting station with freshly collected new data. Lowering of past
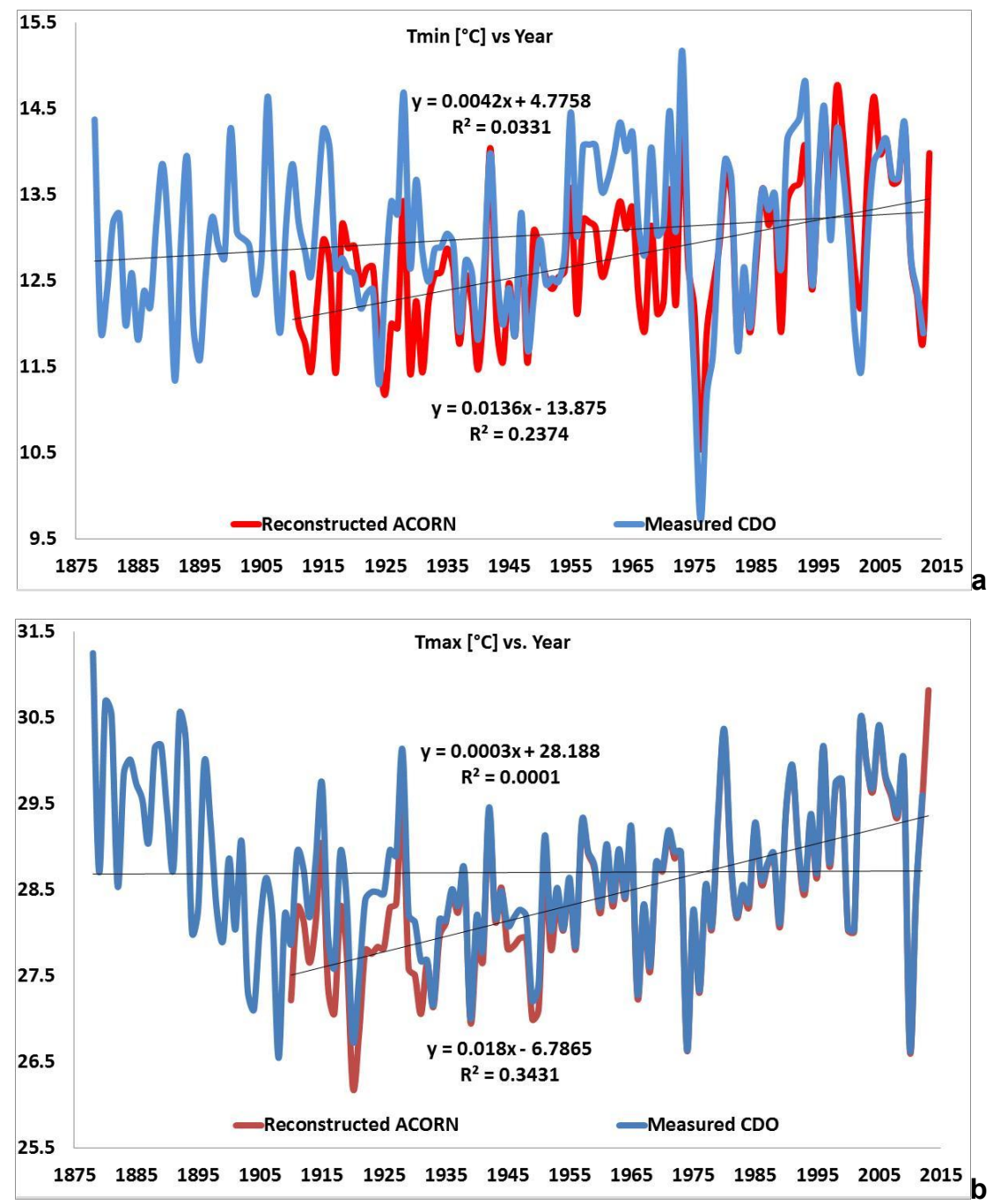

Fig. 1. Corrections of the CDO data set [8] to permit accurate estimations of the Australian temperatures in the ACORN data set [9] in the case of Alice Spring at the center of the Australian desert. (a) minimum temperature, (b) maximum temperature. The CDO data are close to what has been actually measured by thermometers. UHI effects are certainly biasing upwards the trend, that is $+0.0042^{\circ} \mathrm{C} /$ year for the minimum and $+0.0003^{\circ} \mathrm{C} /$ year for the maximum temperatures. The largest warming of the minimum temperature is a sign of UHI. The ACORN data set cut out the pre-1910 data, and shift down the measured temperatures of even more than $1^{\circ} \mathrm{C}$ in the first half of the past century to artificially produce a warming trend of $+0.0136^{\circ} \mathrm{C} /$ year for the minimum and $+0.0180^{\circ} \mathrm{C} /$ year for the maximum temperatures. Data are from $[8,9]$ 
temperatures is actually the norm more than the exception.

Fig. 2 shows the claimed "removal of suspicious records and homogeneity adjustment" in the latest alteration of supporting data of GISS v3 vs v2 for Alice Spring.

The GHCN data to 2011 are available from [12]. The GHCN recently adjusted data 2014 are available from [13]. GISS proposes a monthly average mean temperature that should be the average of maximum and minimum temperatures. The GISS v2 result cover the period January 1880 to December 2011 with 5 missing months, the GISS v3 result covers the period January 1880 to December 2014 with 65 months missed, mostly in recent years. The GISS v2 narrative proposes for Alice Spring a small warming of $0.0008^{\circ} \mathrm{C} /$ year, transformed with the GISS v3 in a huge warming of $0.0124^{\circ} \mathrm{C} /$ year.

Alice Springs (23.8 S,133.9 E)

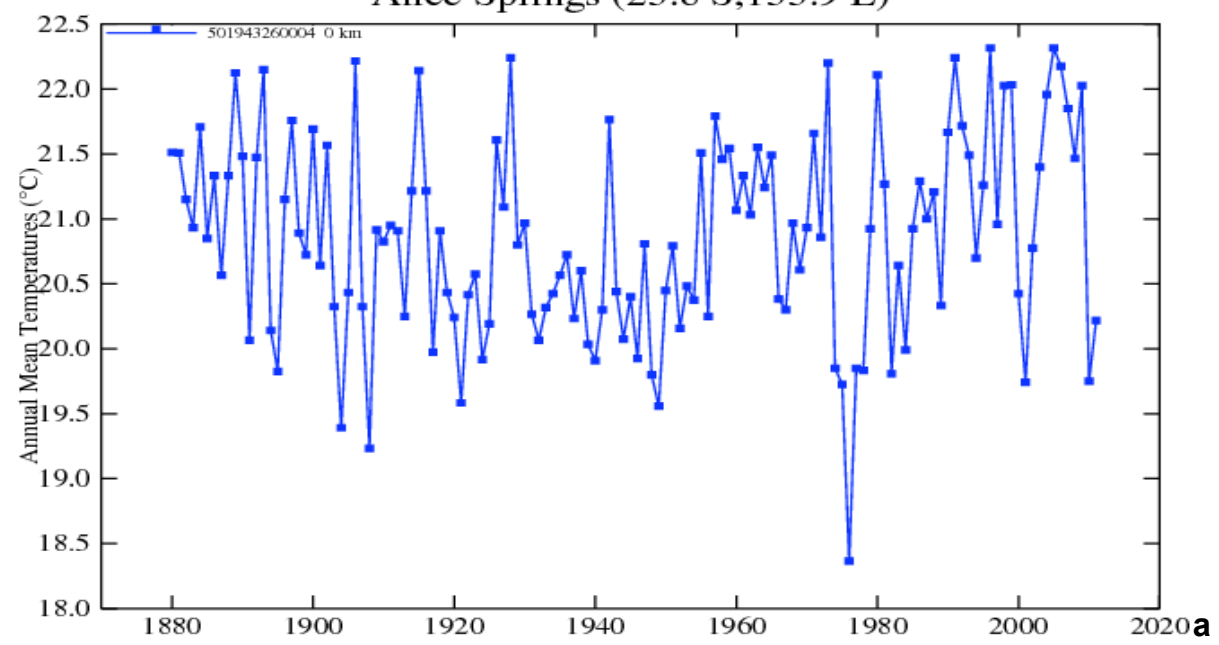

Alice Springs (23.8 S,133.9 E)

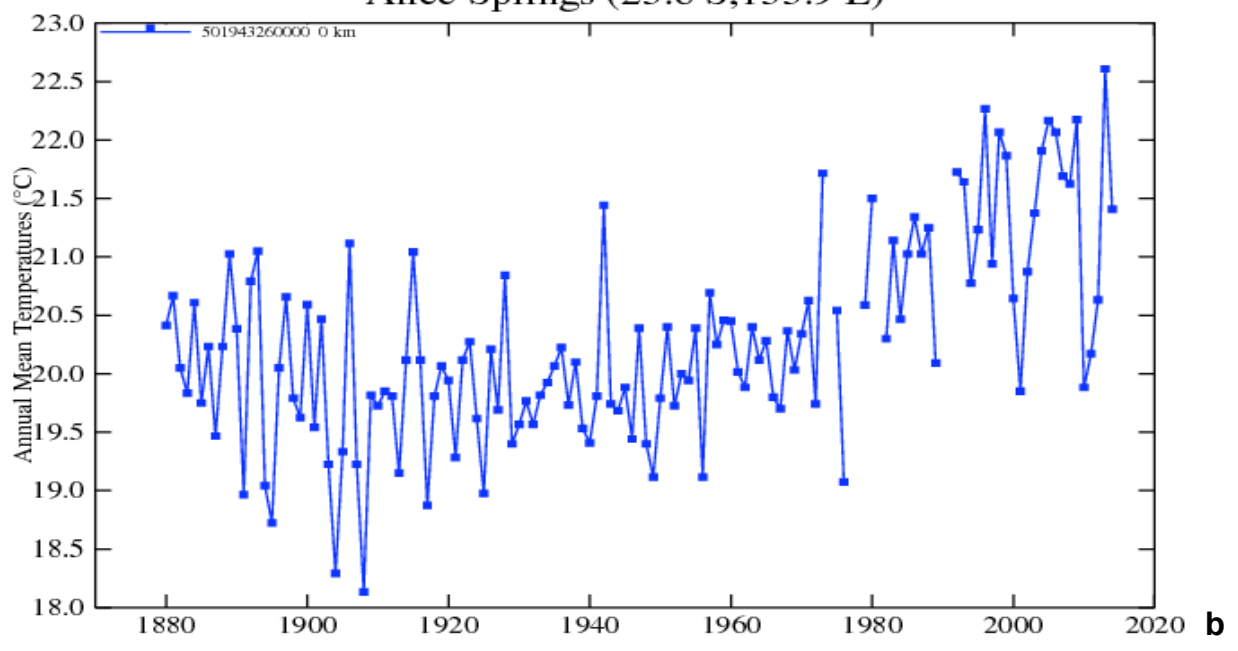

Fig. 2. Comparison of the 2012 GISS v2 temperature record for Alice Spring (a) with the latest GISS v3 reconstruction (b). The GISS v2 narrative proposes for Alice Spring a small warming of $0.0008^{\circ} \mathrm{C} /$ year, transformed with the GISS v3 in a huge warming of $0.0124^{\circ} \mathrm{C} /$ year. The past temperatures are lowered up to $2^{\circ} \mathrm{C}$. Images are taken from [12] \& [13] 
The manipulation GISS v3 vs. v2 is obviously not limited to Alice Spring, but it also includes many other stations of Australia and the rest of the world [14,15]. Fig. 3 presents the case of Willis Island, another remarkable example of tampering. Willis Island is an island in an external territory of Australia, located beyond the Great Barrier Reef in the Coral Sea some 450 $\mathrm{km}$ east of Cairns, Queensland. While the GISS v2 data return a warming trend $0.0010^{\circ} \mathrm{C} /$ year 1939 to 2011 , the GISS v3 arbitrary correction suggests the warming trend is $0.0109^{\circ} \mathrm{C} /$ year 1939 to 2015 , roughly one order of magnitude larger. As the claims global warming is threatening the Great Barrier Reef is not that evident in the v2 data (Willis Island is the only result for the area), the v3 manipulation certainly serves the purposes and further contribution to the global trend.

Willis Island is a very small island. It is about 500 meters long by 150 metres wide, rising to about 9 meters above sea level. It is the only permanently inhabited island in Australia's Coral Sea Islands Territory. The Australian Bureau of Meteorology has a weather monitoring station on the island usually occupied by four weather observers living on the island. The Stevenson screened thermometer is located very close to the dwelling.
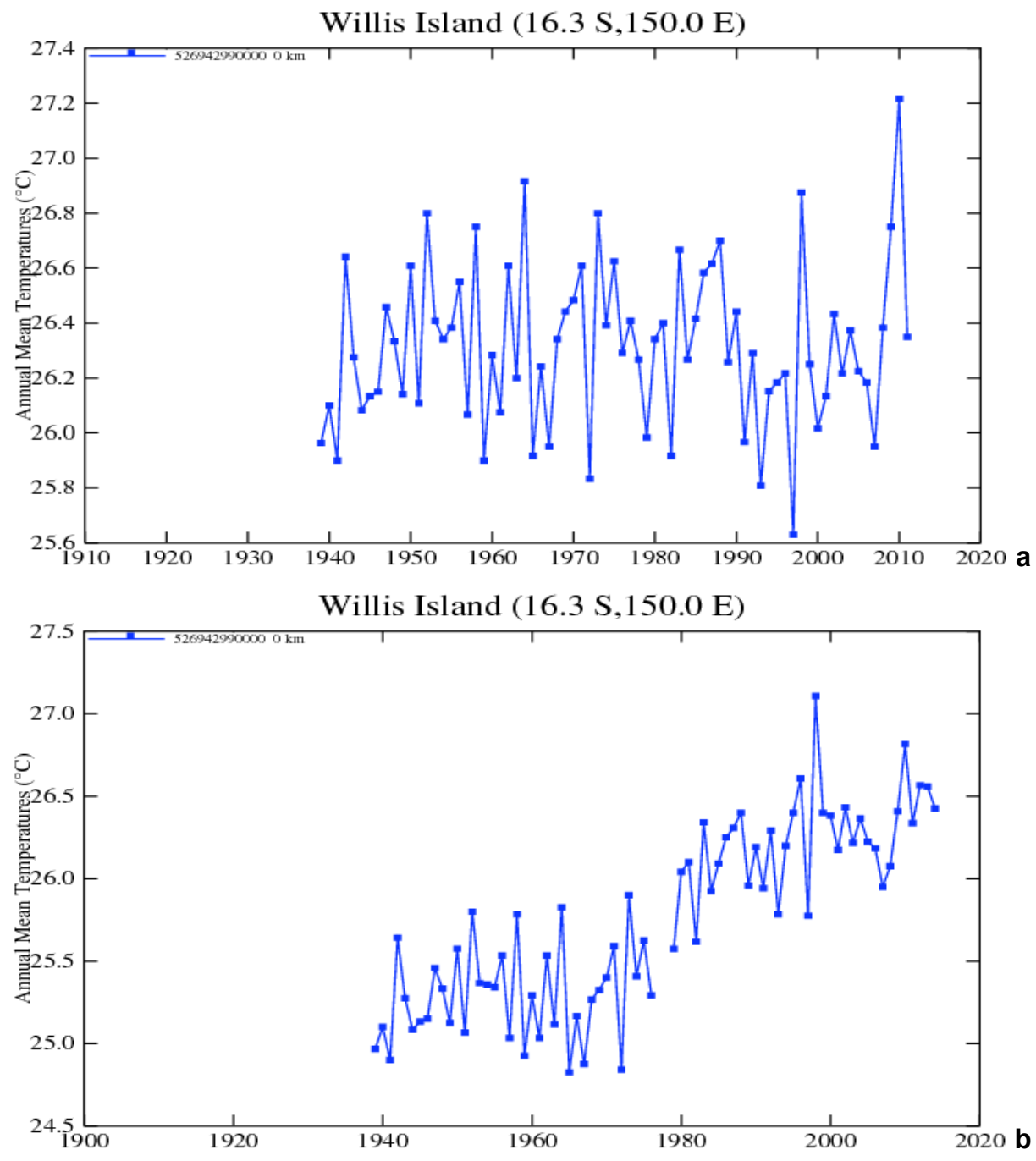

Fig. 3. Comparison of the 2012 GISS v2 temperature record for Willis Island (a) with the latest GISS v3 reconstruction (b) The GISS v2 narrative proposes for Willis Island a small warming of $0.0010^{\circ} \mathrm{C} /$ year transformed with the GISS v3 in a ten times larger warming of $0.0109^{\circ} \mathrm{C} /$ year. The past temperatures are lowered up to $1^{\circ} \mathrm{C} \mathrm{v} 3 \mathrm{vs}$. v2. Images are taken from $[12,13]$ 
By using the CDO [8] data base, the actual trends that may be computed for Willis Island are 0.0019 and $0.0086^{\circ} \mathrm{C} /$ year over the time window 1921 to 2015 for the maximum and minimum temperatures respectively. This translates in a warming of $0.0052^{\circ} \mathrm{C} /$ year for the average temperature. Over the GISS time window 1939 to 2015 , the trends are -0.0005 and $0.0109^{\circ} \mathrm{C} /$ year for the maximum and minimum temperatures respectively. This translates in a $0.0052^{\circ} \mathrm{C} / \mathrm{year}$ for the average temperature. As the maximum temperature trend that better evidences a warming, Willis Island has clearly no remarkable warming in the CDO data. The station is not included in the ACORN data base [9].

A proper assessment of the warming trend should not follow neglecting or arbitrarily cooling down the temperatures measured in the past, and should certainly account properly for the formation of urban heat island.

\section{CONCLUSION}

The CSIR and Year Book temperature datasets are unadjusted records compiled in the mid- $20^{\text {th }}$ century. They differ from the latest BOM records that are adjusted in both CDO and ACORN.

There is no reason why the ACORN data set should be considered more accurate than the CSIR and Year Book data sets. The CSIR and Year Book temperature datasets include the first 85 years of temperature recording at most weather stations across Australia in a network more than twice as large as ACORN. The CSIR and Year Book averages are a legitimate historic record indicating climate warming has been significantly less than calculated with the adjusted data since 1910 in the ACORN. Actually, the reliability of the ACORN data set is minimal as the selection of stations to include or neglect and the correction of the measured temperatures is arbitrary.

A proper assessment of the warming trend should be based on the CDO data base cleared of UHI effects. The correction for UHI formation would increase and not lower the temperatures of the past, or alternatively lower the present temperatures, for a drastically reduced warming trend.

As commented in [11], we do have serious doubts that the global and local temperatures measured at the thermometers may rise of $2^{\circ} \mathrm{C}$ by the end of this century as claimed by the
IPCC [16] or $4^{\circ} \mathrm{C}$ by the end of this century as claimed by the local intergovernmental scientists [17] used to double or triple any catastrophic estimation.

Hopefully, the practice of correcting the pastmeasured quantities that do not verify the climate models expectations for the present will be over before the year 2100 so our descendants will not be forced to believe today's temperature were $4^{\circ} \mathrm{C}$ lower.

\section{COMPETING INTERESTS}

The author has no financial and personal relationships with other people or organizations that could inappropriately influence (bias) their work.

\section{REFERENCES}

1. Boretti A. Statistical analysis of the temperature records for the northern territory of Australia. Theoretical and Applied Climatology. 2013;114(3):567-573.

2. Parker A. The temperature record of Alice Spring, Northern Territory of Australia revisited, Environmental Science: An Indian Journal. 2014;10(3):ESAIJ_2156.

3. Parker A. Melbourne urban heat island contamination of temperature trend maps in Victoria, Australia. Nonlinear Engineering. 2014a;2(1-2):39-62.

4. Parker $A$, Ollier CD. The warming of Australia is man-made, but not by carbon dioxide. Environmental Science: An Indian Journal. 2014;10(5):ESAIJ 2544.

5. Gillham C. Pre 1931 CSIR, 1911-40 Year Book, RAW and ACORN temperature comparisons; 2015.

Available:www.waclimate.net/year-bookcsir.html

6. Council for Scientific and Industrial Research (CSIR) Meteorological Data for Certain Australian Localities; 1933. Available: www.waclimate.net/csir.pdf

7. Commonwealth of Australia, Official Year Book of the Commonwealth of Australia, 1953;\#39.

Available:www.waclimate.net/year-bookcsir.html

8. Bureau of Meteorology (BOM), Climate Data Online (CDO); 2014a. Available:www.bom.gov.au/climate/data/

9. Bureau of Meteorology (BOM), ACORN: The Australian Climate Observations Reference Network - Surface Air 
Temperature (ACORN-SAT); 2014b. Available:www.bom.gov.au/climate/change /\#tabs=Tracker\&tracker=site-networks

10. Hunt H. On the Climate of the YassCanberra District; 1910.

Available:www.waclimate.net/canberrapre1909.pdf

11. Parker A. Global temperatures may not increase by $4^{\circ} \mathrm{C}$ by the end of this century. Current Science. 2014c;107(03).

12. National Aeronautics and Space Administration Goddard Institute for Space Studies, Station Data Based on GHCN v2, Ending in Oct 2011; 2012. Available:data.giss.nasa.gov/gistemp/statio n data v2l

13. National Aeronautics and Space Administration Goddard Institute for Space Studies Station Data; 2014

Available:data.giss.nasa.gov/gistemp/statio $\underline{\mathrm{n} \text { datal }}$
14. Homewood P. All of Paraguay's Temperature Record Has Been tampered with; 2015.

Available:notalotofpeopleknowthat.wordpre ss.com/2015/01/26/all-of-paraguaystemperature-record-has-been-tamperedwith/

15. Homewood P. Iceland's sea ice years disappear in GHCN Adjustments; 2015. Available:notalotofpeopleknowthat.wordpre ss.com/2012/01/28/icelands-sea-ice-yearsdisappear-in-ghcn-adjustments/

16. Intergovernmental Panel on Climate Change (IPCC), Fifth Assessment Report (AR5); 2013.

Available:www.ipcc.ch/report/ar5/

17. Sherwood SC, Bony S, Dufresne JL. Spread in model climate sensitivity traced to atmospheric convective mixing, Nature. 2014;505:37-42.

(c) 2015 Parker; This is an Open Access article distributed under the terms of the Creative Commons Attribution License (http://creativecommons.org/licenses/by/4.0), which permits unrestricted use, distribution, and reproduction in any medium, provided the original work is properly cited.

Peer-review history:

The peer review history for this paper can be accessed here: http://www.sciencedomain.org/review-history.php?iid=1001\&id=33\&aid=8854 